\title{
WORKSHOP INTERNET-OF-THINGS UNTUK GURU DAN SISWA SEKOLAH MENENGAH DI PURWAKARTA, JAWA BARAT, GUNA MENUNJANG KOMPETENSI ERA INDUSTRI 4.0
}

\author{
Syifaul Fuada ${ }^{1}$, Ichwan Nul Ichsan ${ }^{2}$, Hafiyyan Putra Pratama ${ }^{3}$, Dewi Indriati \\ Hadi Putri ${ }^{4}$, Galura Muhammad Suranegara ${ }^{5}$, Endah Setyowati ${ }^{6}$, Ahmad Fauzi ${ }^{7}$
}

\author{
${ }^{1}$ Universitas Pendidikan Indonesia. Email: syifaulfuada@upi.edu \\ 2 Universitas Pendidikan Indonesia. Email: ichwannul.ichsan90@upi.edu \\ 3 Universitas Pendidikan Indonesia. Email: hafiyyan@upi.edu \\ 4 Universitas Pendidikan Indonesia. Email: dewiindri@upi.edu \\ 5 Universitas Pendidikan Indonesia. Email: galurams@upi.edu \\ 6 Universitas Pendidikan Indonesia. Email: endahsetyowati@upi.edu \\ 7 Universitas Pendidikan Indonesia. Email: ahmad.fauzi@upi.edu
}

\begin{abstract}
Internet of Things (IoT) is one of the technological paradigms developed in the industrial revolution 4.0. The concept of IoT is an object can transfer data over a network without interaction from human-tohuman or from human-to-computer. One of the IoT implementations in the education sector is the attendance system using IoT-based Radio Frequency Identification (RFID). The attendance machines such as fingerprints and face recognition have a relatively high-cost compared to RFID machines. Hence, if the number of attendance machines within the School is limited, it will be less efficient for a large number of students and vulnerable to queuing. The RFID implementation in the Education sector was socialized through a Workshop with students and teachers of the secondary schools in Purwakarta, West Java, as the participants. To provide additional insight and expertise about the RFID-IoT concept to the workshop participants, this community service activity needs to be done. Several benefits will be obtained through this workshop, including saving paper use and efficiency, because the RFID-based IoT can reduce the teachers' workload in processing the student attendance lists. Teachers are also invited to this workshop so they can guide their students and pass on the additional skills. Moreover, the invited teacher will teach new knowledge related to workshop material to other students in the School.
\end{abstract}

Keywords: Internet-of-things, RFID, Mesin Kehadiran, Workshop, Purwakarta

\begin{abstract}
ABSTRAK
Internet of Things (IoT) merupakan salah satu paradigma teknologi yang dikembangkan dalam revolusi industri 4.0. Konsep IoT adalah suatau objek dapat mentransfer data lewat jaringan tanpa adanya interaksi dari manusia ke manusia ataupun dari manusia ke perangkat komputer. Salah satu implementasinya pada bidang pendidikan yaitu sistem kehadiran menggunakan Radio Frequency Identification (RFID) berbasis teknologi IoT. Mesin kehadiran seperti fingerprint dan face recognition memiliki harga yang relatif mahal dibandingkan mesin RFID. Sementara, jika jumlah mesin kehadiran yang ada di sekolah terbatas, hal ini sedikit kurang efisien untuk jumlah siswa yang sangat banyak dan rentan menimbulkan antrian. Implementasi RFID di bidang Pendidikan ini disosialisasikan melalui
\end{abstract}


sebuah Workshop dengan siswa dan Guru dari sekolah menengah di Purwakarta, Jawa Barat sebagai peserta. Untuk dapat memberikan tambahan wawasan dan keterampilan mengenai mesin kehadiran RFID dengan konsep IoT kepada peserta Workshop, maka pengabdian masyarakat ini perlu dilakukan. Beberapa manfaat akan didapat memalui workshop ini, termasuk menghemat penggunaan kertas dan efisiensi karena RFID berbasis IoT mengurangi beban kerja guru dalam mengolah data kehadiran siswa. Guru turut diundang dalam workshop ini agar mereka dapat membimbing siswanya dan menularkan tambahan keterampilan dan wawasan yang didapat dari kegiatan PKM ini kepada siswa lainnya di sekolah..

Kata Kunci: Internet-of-things, RFID, Workshop, Purwakarta

\section{PENDAHULUAN}

Saat ini, penggunaan sistem Radio Frequency Identification (RFID) telah banyak diterapkan di berbagai sektor seperti transportasi, sistem pembayaran digital, sistem identifikasi maupun pada sistem pendidikan. Berkaitan dengan bidang Pendidikan, salah satu realisasi dari RFID adalah berupa sistem kehadiran yang terhubung dengan internet (Aji et al., 2020). Teknologi RFID yang dipadukan dengan Internet-of-Things (IoT) untuk sistem absensi tersebut menawarkan beberapa benefit, antara lain adalah dapat mengurangi penggunaan kertas untuk absensi, selain itu juga dapat mengurangi beban kerja pegawai di Sekolah/Kampus dalam merekap dan mengawasi kehadiran pegawai atau siswa karena semuanya dapat dipantau via internet (Fauziah et al., n.d.) (E. B. Setiawan \& Kurniawan, 2015). Aplikasi mesin kehadiran berbasis RFID-IoT di lingkungan sekolah SMA/SMK disinyalir dapat mempermudah guru dalam hal presensi siswa-siswinya.

Berdasarkan observasi, beberapa sekolah tingkat menengah atas dan kejuruan di Purwakarta masih menggunakan sistem kehadiran manual, yaitu dengan memanggil siswa satu per satu. Terdapat beberapa kelemahan pada sistem yang konvensional tersebut, diantaranya adalah Guru sulit untuk melacak kembali data kehadiran siswa dari pertemuan sebelumnya, menganalisis data kehadiran siswa, dan memonitoring kehadiran siswa secara real-time. Selain itu, juga mengurangi efektifitas jam belajar siswa di kelas karena waktu tatap muka dikurangi dengan durasi presensi oleh guru (Purwiantono et al., 2019). Apabila lembar kehadiran tersebut diisi oleh siswa sendiri, maka dapat memunculkan peluang untuk melakukan tindakan "titip absen" (Widayanti, 2019).

Disisi lain, beberapa sekolah SMA/SMK di Purwakarta sudah menggunakan fingerprint reader atau face recognition dalam proses kehadirannya. Namun sistem tersebut kurang efisien untuk jumlah siswa yang sangat banyak dan rentan menimbulkan antrian panjang apabila perangkat yang tersedia terlalu sedikit. Pemasangan mesin fingerprint reader yang cukup banyak pun dirasa kurang efektif mengingat harganya yang relatif mahal. Ketika aspek low-cost dengan fungsi yang sama, menjadi pertimbangan utama, maka mesin absensi berbasis RFID-IoT dapat menjadi solusi. Sistem tersebut dapat dikembangkan oleh sekolah sendiri dengan memanfaatkan potensi beberapa siswa-siswi nya yang cerdas, didukung oleh Guru yang berkompeten dibidang teknologi, dan kebijakan sekolahnya dalam menyiapkan teknologi buatan kolaborasi siswa \& guru di sekolah tersebut.

Namun, untuk mencapai itu, diperlukan suatu dukungan dari Perguruan Tinggi sebagaimana tiga pilar Tridharma PT, diantaranya adalah menyiapkan trainer atau alat peraga yang dapat digunakan oleh siswa/siswi SMK (Wagyana, 2019). Langkah dibidang pengabdian adalah dengan melalui program pelatihan yang ditujukan kepada siswa/siswi beserta Guru. IoT dan RFID merupakan hal yang baru bagi sebagian dari mereka sehingga 
urgensi transfer pengetahuan dari PT ke sekolah menjadi prioritas. Program pelatihan (workshop)/penyuluhan/sosialisasi teknologi ke sekolah-sekolah juga merupakan salah satu usaha dalam menyiapkan kompetensi siswa agar mampu bersaing di era modern serba teknologi seperti saat ini (Manfaluthy \& Ekawati, 2019) (Afriliana et al., 2018) (Irmansyah \& Madona, 2019) (Ananda \& Amin, 2019). Ketika mereka memasuki dunia kerja, mereka harus siap menghadapi revolusi industri 4.0. Guru juga berperan penting dalam transfer ilmu pada jenjang SMA/SMK yang berhubungan dengan teknologi (H. S. Setiawan, 2018), karena penerapan skill teknologi harus dimulai dari tingkat pendidikan menengah dimana Guru juga memiliki tanggung jawab akan hal ini.

Berdasarkan alasan tersebut, Program Pengabdian kepada Masyarakat (PkM) ini berupaya untuk menerapkan IoT pada bidang pendidikan melalui Workshop yang diberikan kepada guru dan siswa dari beberapa sekolah menengah atas dan kejuruan di Kab. Purwakarta, Jawa Barat, untuk membuat mesin kehadiran berbasis RFID sebagai langkah awal menyongsong industri 4.0. Penggunaan RFID ini diharapkan dapat memberikan beberapa manfaat seperti ramah lingkungan karena adanya pengurangan penggunaan kertas untuk sistem kehadiran dan efisiensi, yaitu dapat mengurangi beban kerja guru serta efektifitas waktu dalam proses belajar mengajar. Bagi siswa, pengenalan teknologi ini akan membuka wawasan dan menambah keterampilan tentang penerapan konsep IoT di bidang Pendidikan (Setyowati et al., 2019). Selain itu, juga untuk meringankan beban kerja guru secara keseluruhan. Pelaksanaan dari workshop atau pengabdian kepada Masyarakat berbasis penerapan bidang ilmu ini juga sejalan dengan visi-misi Program Studi Sistem Telekomunikasi Universitas Pendidikan Indonesia (UPI) Kampus Purwakarta yang merupakan pelaksana program.

\section{METODE PELAKSANAAN}

Melalui Workshop ini para peserta akan diberikan pelatihan selama satu hari dan diberikan materi-materi yang menunjang dalam proses instalasi serta pengoperasian sistem RFID tersebut. Dengan demikian, peserta mendapat keterampilan serta wawasan mengenai perkembangan dan contoh aplikasi IoT yang secara tidak langsung akan meningkatkan minat siswa terhadap IoT saat ini. Secara garis besar pelaksanaan program pengabdian kepada masyarakat ini dilaksanakan dalam beberapa tahapan, yaitu:

\section{Persiapan}

Pada tahap ini dilakukan persiapan yang mendukung pelaksanaan kegiatan Workshop sebagai berikut:

a. Menjalin hubungan kerjasama dengan PPTIK ITB sebagai penyedia mesin absensi.

b. Menentukan lokasi dan tanggal pelaksanaan Workshop.

c. Menentukan sekolah-sekolah yang akan diundang untuk mengikuti Workshop.

d. Melibatkan mahasiswa dalam pelaksanaan PkM.

e. Pembuatan surat undangan ke sekolah-sekolah, surat pemberitahuan ke pimpinan UPI Purwakarta, serta surat pemberitahuan ke petugas keamanan dan petugas kebersihan.

f. Pembuatan desain sertifikat untuk peserta, pelaksana, dan panitia. Selanjutnya desain spanduk, backdrop, ID card, dan stiker pada smartcard.

g. Kunjungan ke sekolah-sekolah undangan sekaligus mengkonfirmasi kehadirannya. 


\section{Pelaksanaan}

Kegiatan Workshop ini dimulai dengan pemaparan tujuan Workshop, pemberian materi mengenai IoT, pengenalan alat dan identifikasi komponen yang digunakan, perancangan mesin kehadiran, instalasi perangkat lunak yang digunakan dan terakhir percobaan alat.

\section{Evaluasi}

Untuk mengetahui respon peserta setelah mengikuti Workshop IoT, dilakukan survey kepuasan peserta yang dilakukan dengan memberikan lembar survei pada akhir acara. Hasil dari survei tersebut diharapkan dapat menjadi masukan bagi kami agar dapat melayani peserta pengabdian kepada masyarakat lebih baik kedepannya.

\section{HASIL DAN PEMBAHASAN}

Seperti yang telah disampaikan pada Bab Metode, secara garis besar, proses pelaksanaan PkM terbagi atas tiga tahap yakni persiapan, pelaksanaan, dan evaluasi (respon peserta Workshop). Dengan demikian, realisasi Workshop mengacu pada Metode. Secara garis besar, kongkrit pelaksanaannya adalah sebagai berikut ini:

\section{Persiapan}

Tim PkM mengundang peserta sebanyak 15 sekolah tingkat menengah di Kabupaten Purwakarta, Jawa Barat, dengan komposisi satu guru dan satu siswa dari masing-masing sekolah. Adapun persiapan awal terdiri atas dua tahap, tahap pertama adalah sebagai berikut:

1. Mempersiapkan desain, kebutuhan alat dan bahan untuk mesin kehadiran RFID, dalam hal ini tim PkM bekerja sama dengan PPTIK ITB dalam mempersiapkan desain perangkat IoT berbasis RFID. Penggunaan mesin kehadiran ini sangat mudah berbasis kartu RFID, pengguna hanya perlu melakukan tap kartu yang mereka miliki ke mesin kehadiran. Secara teknologi mesin kehadiran ini dibuat menggunakan konsep IoT dimana akan banyak mesin absensi yang terhubung dengan server data. Kemudian dalam pertukaran data antara mesin dan server tidak menggunakan REST API tetapi melalui konsep antrian (queue) melalui message broker. Banyaknya data yang akan diterima dari siswa sekolah menengah se-Purwakarta harus diantisipasi dengan melakukan clustering pada message broker sehingga data yang masuk tidak dilayani hanya satu service tapi oleh beberapa service yang bekerja secara bergantian. Proses transfer data pada mesin RFID dapat dilihat pada Gambar 1. Jika diimplementasikan dalam jangka waktu yang lama maka akan terkumpul banyak data kehadiran yang
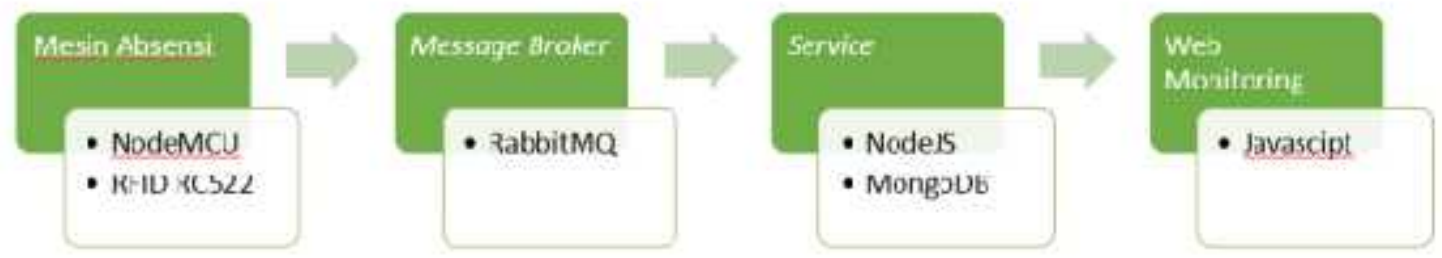

Gambar 1 Diagram proses mesin absensi berbasis RFID

Pada masing-masing mesin kehadiran yang diberkan kepada peserta workshop, terdiri atas beberap komponen elektronika antara lain RFID RC522 sebagai alat pembaca kartu berbasis RFID. Selain itu terdapat juga nodeMCU berbasis WiFi sebagai controller untuk 
mengirimkan data-data menuju server melalui internet. Gambar 2 merupakan komponenkomponen yang digunakan dalam Workshop dimana masing-masing perwaklian sekolah (1 guru \& 1 siswa) medapatkan 1 kit mesin absensi, terdiri atas Box, Adaptor, RFID RC522, kartu \& tag, konektor PCB, NodeMCU, Housing-Header, kabel USB \& konenktor, Buzzer, serta komponen pasif elektronika. Untuk spesifikasi masing-masing komponen yang digunakan pada mesin kehadiran RFID dapat dilihat pada Tabel 1 .

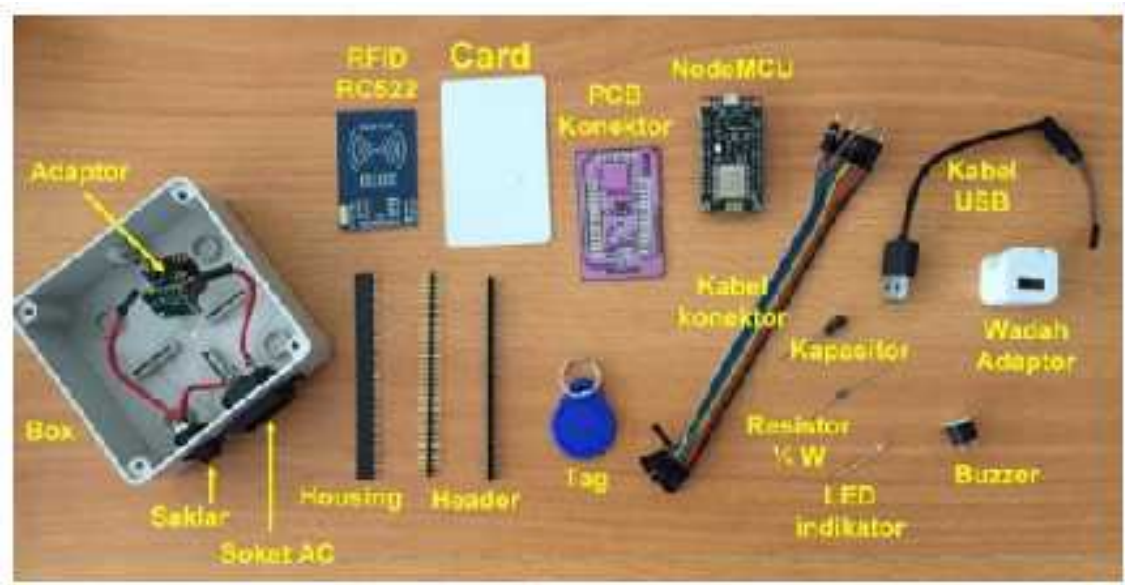

Gambar 2 Komponen-komponen mesin kehadiran berbasis RFID

Tabel 1 Spesifikasi mesin kehadiran berbasis RFID keluaran PPTIK-ITB

\begin{tabular}{|c|c|}
\hline Komponen & Keterangan \\
\hline \multirow[t]{2}{*}{ Buzzer } & 1.Tegangan: $5 \mathrm{v}$ \\
\hline & 2.Arus Maks : $30 \mathrm{~mA}$ \\
\hline \multirow[t]{2}{*}{ Kabel } & $\begin{array}{l}\text { 1.Kabel Jumper cable dupont pelangi } 10 \mathrm{~cm} 10 \text { male female header } \\
\text { cable pin - Female Female }\end{array}$ \\
\hline & $\begin{array}{l}\text { 2.Kabel Jumper cable dupont pelangi } 30 \mathrm{~cm} 30 \text { male female header } \\
\text { cable pin - Female Female }\end{array}$ \\
\hline Box & - \\
\hline Saklar On/Off & Saklar on/off kecil 2 pin \\
\hline Socket AC & Socket AC listrik 3 Pin \\
\hline Adaptor & Charger Adaptor USB 500mAh 5v \\
\hline Housing LED & $5 \mathrm{~mm}$ \\
\hline Header & 1.Pitch Size : $2.54 \mathrm{~mm}$ \\
\hline \multirow[t]{3}{*}{ Male/Female } & 2.Pin : 40 pin \\
\hline & 3.Tipe : Female-Male \\
\hline & 4.Warna Pin : kuning/gold \\
\hline \multirow[t]{9}{*}{ NodeMCU } & 1.Chip mikrokontroler : ESP-8266E \\
\hline & $\begin{array}{l}\text { 2.ESP-12 yg memiliki GPIO, PWM, ADC, I2C dan 1-WIRE interface. } \\
\text { 3.USB to serial chip (dapat diprogram via komputer) }\end{array}$ \\
\hline & 4.Pin I/O digital : 11 buah (kecuali pin D0) \\
\hline & 5.Pin I/O analog : 1 buah, $3.2 \mathrm{~V} \max$ \\
\hline & 6.Tegangan operasi : $3.3 \mathrm{~V}$ \\
\hline & 7.Clock speed : $80 \mathrm{Mhz} / 160 \mathrm{Mhz}$ \\
\hline & 8.Flash : 4M \\
\hline & 9.USB controller $:$ CH340G \\
\hline & 10. Dimensi : $32 \mathrm{~mm} \times 25 \mathrm{~mm}$ \\
\hline LED & LED super \\
\hline Kabel USB & charge dan sync data (pindah data) \\
\hline
\end{tabular}




$\begin{array}{ll}\text { Resistor } & \text { 330R 330 Ohm Resistor Stackpole SEI RNMF Audiograde P/N: } \\ & \text { RNMF14FTC330R } \\ \text { RFID RC522 } & \text { Frekuensi operasi: } 13.56 \mathrm{MHz} \\ & \text { terdiri dari: reader, kartu, tag }\end{array}$

2. Penentuan lokasi, tanggal pelaksanaan dan rundown acara PkM. Workshop diselenggarakan di lingkungan kampus UPI Purwakarta dengan alasan efisiensi. Sementara pemilihan tanggal pelaksanaan kegiatan Workshop ini ditentukan pada tanggal 14 Agustus 2019 dengan pertimbangan yaitu agar tidak mengganggu jadwal perkuliahan.

3. Melakukan rekrutasi panitia tambahan sebanyak 15 mahasiswa untuk membantu terselenggaranya acara Workshop ini mulai dari persiapan hingga acara selesai. Sebagian mahasiswa dilibatkan untuk menjadi asisten instruktur dan sebagian lainnya dilibatkan untuk mendukung kelancaran acara di bidang lain. Sebelum Workshop dilaksanakan, asisten instruktur dibekali dengan pelatihan khusus sehingga siap guna untuk dilibatkan dalam Workshop. Pelatihan yang diberikan berupa pemberian materi mengenai mesin RFID, dari komponen dasar, perakitan mesin RFID, melakukan penyolderan hingga menghubungkan mesin RFID dengan server, yang dipandu oleh Dosen-dosen Sistem Telekomunikasi UPI Purwakarta, yaitu Syifaul Fuada, S.Pd., MT., Dewi Indriati Hadi Putri, S.Pd., M.T., Hafiyyan Putra Pratama, S.T., M.T., dan Endah Setyowati, S.T., M.T.

4. Penentuan sekolah-sekolah yang diundang, dalam hal ini dipilih sekolah-sekolah terdekat disekitar kampus UPI Purwakarta dengan alasan bahwa sekolah-sekolah yang berada di kota kabupaten adalah sekolah-sekolah unggulan di kabupaten tersebut sehingga tidak terlalu sulit untuk dapat menerapkan mesin RFID di sekolahnya (Setyowati et al., 2019). Beberapa sekolah yang kami undang tersebut adalah SMAN 1 Purwakarta, SMAN 2 Purwakarta, SMAN 3 Purwakarta, SMKN 1 Purwakarta, SMKN 2 Purwakarta, SMKN 3 Purwakarta, MAN Purwakarta, MA Al-Huda Jatiluhur, SMAN 1 Jatiluhur, SMAN 1 Bungursari, SMK Purnawarman, SMK Taruna Sakti, SMKN 1 Plered, SMAN 1 Pasawahan, dan SMKN 1 Sukatani.

5. Mobilisasi mahasiswa yang akan membantu selama pelaksanaan PkM, dalam hal ini ditentukan 15 Mahasiswa Tk. I. Mereka dibagi kedalam 5 divisi utama yakni Dokumentasi \& Publikasi, acara, perlengkapan, medis \& humas, dan asisten instruktur.

Setelah kelima kegiatan di atas selesai dilaksanakan, maka tahap persiapan kedua adalah sebagai berikut:

1. Pembuatan surat undangan ke sekolah-sekolah, surat pemberitahuan dan undangan kepada direktur UPI Purwakarta, serta surat pemberitahuan ke petugas keamanan dan petugas kebersihan.

2. Dilakukan sosialisasi mengenai acara Workshop sekaligus pemberian surat undangan kepada lima belas sekolah tersebut pada tanggal yang tertera pada Tabel 2,

Tabel 2 Tanggal Pemberian Surat Undangan

\begin{tabular}{|c|c|c|}
\hline No. & 29 Juli 2019 & 30 Juli 2019 \\
\hline 1. & SMKN 2 Purwakarta & SMAN 1 Pasawahan \\
\hline 2. & SMK Purnawarman & SMAN 1 Purwakarta \\
\hline 3. & SMAN 1 Jatiluhur & SMKN 1 Sukatani \\
\hline 4. & MA Al-Huda Jatiluhur & SMKN 1 Plered \\
\hline 5. & SMK Taruna Sakti & \\
\hline 6. & SMKN 3 Purwakarta & \\
\hline
\end{tabular}




\section{MAN Purwakarta}

8. SMAN 1 Bungursari

3. Menghubungi kembali sekolah yang telah diundang untuk mendapatkan konfirmasi kehadirannya. Dari lima belas sekolah yang kami undang, ada dua sekolah yang memberikan konfirmasi secara mendadak tidak dapat menghadiri acara Workshop ini dikarenakan bertepatan dengan acara lain di sekolah tersebut.

4. Pembuatan sertifikat untuk peserta, pelaksana, dan panitia dimana masing-masing didesain berbeda. Selanjutnya desain spanduk, backdrop, ID card, dan stiker pada smartcard.

\section{Pelaksanaan}

Setelah proses persiapan, tahap selanjutnya adalah pelaksanaan. Kegiatan dilaksanakan satu hari yakni pada tanggal 14 Agustus 2019 bertempat di Gd. Baru Lt. II kampus UPI Purwakarta. Kegiatan dimulai pada pukul 08.00 WIB dengan diawali oleh Laporan ketua pelaksana Workshop IoT, yakni Endah Setyowati, S.T., M.T., (Gambar 4a) dilanjutkan dengan sambutan oleh Wakil Direktur UPI Purwakarta, yakni Dr. Agus Muharam, M.Pd (Gambar 4b) dan dibuka secara resmi oleh Direktur UPI Purwakarta, Prof. Turmudi, M.Ed., M.Sc., Ph.D (Gambar 4c) dengan total peserta sebanyak 24 orang terdiri dari guru dan siswa dari 13 sekolah.

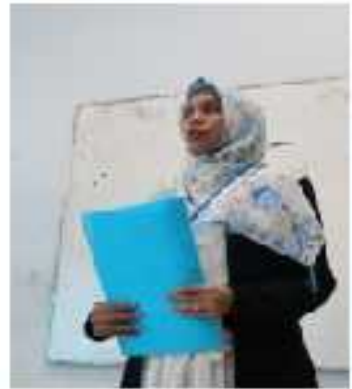

(a)

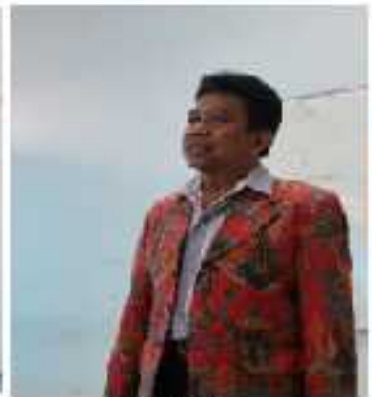

(b)

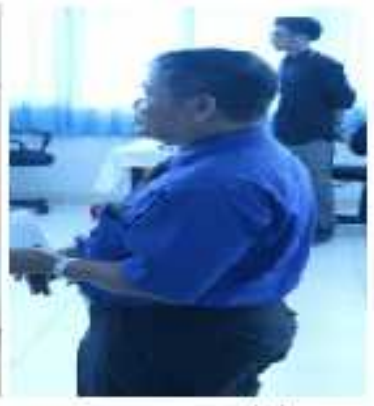

(c)

Gambar 4 Dokumentasi acara pembukaan

(a) laporan ketua pelaksana; (b) sambutan wakil direktur; (c) pembukaan secara resmi oleh direktur

Selanjutnya, pemberian materi singkat mengenai definisi IoT, stuktur sistem, komponen yang diperlukan, dan contoh-contoh aplikasinya oleh salah satu Dosen Sistel, yakni Hafiyyan Putra Pratama, S.ST., M.T. (Gambar 5a). Pembekalan awal ini sangat penting agar para peserta mengenali dan memahami mengenai sistem yang dipraktikkan pada kegiatan PkM ini. Adapun materi yang disampaikan pada sesi awal adalah sebagai berikut:

- Sejarah Internet of things, materi ini diberikan untuk memberikan gambaran kepada peserta internet of things adalah hal yang sudah ditemukan dan baru menjadi penting saat-saat ini.

- Data Center

- Konektifitas antar perangkat

- Pengenalan Mesin Absensi berbasis RFID

- Pengenalan komponen-komponen penyusun mesin absensi berbasis RFID

Pada sesi kedua, peserta diberikan Kit praktikum (mesin kehadiran berbasis RFID) dan diarahkan oleh Dewi Indriati Hadi Putri, S.Pd., M.T. (Gambar 5b) dan juga Syifaul Fuada, S.Pd., 
M.T. Instruktur dibantu oleh asisten yang berjumlah 15 orang. Mereka merupakan mahasiswa pilihan kampus UPI Purwakarta. Kegiatan praktikum mencakup perakitan, penyolderan, dan antarmuka ke server dimana aplikasinya bersifat open source sehingga bebas dimodifikasi sesuai kebutuhan peserta (Gambar 6). Untuk mempermudah perakitan, para peserta dibekali buku panduan yang telah disusun oleh instruktur seperti yang ditunjukkan pada Gambar 7.

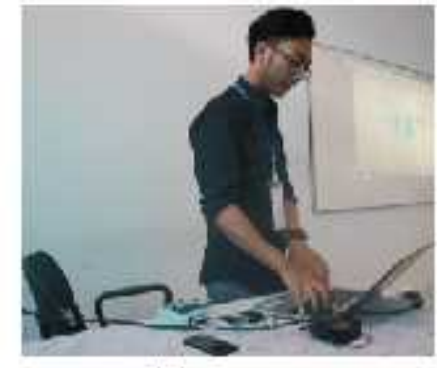

$[$ [i]

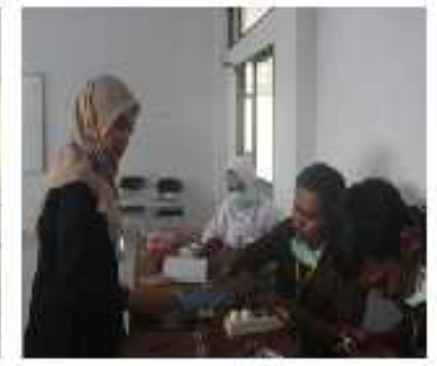

(b)

Gambar 5 Dokumentasi acara pelaksanaan (a) pemberian materi workshop; (b) pengarahan perakitan komponen

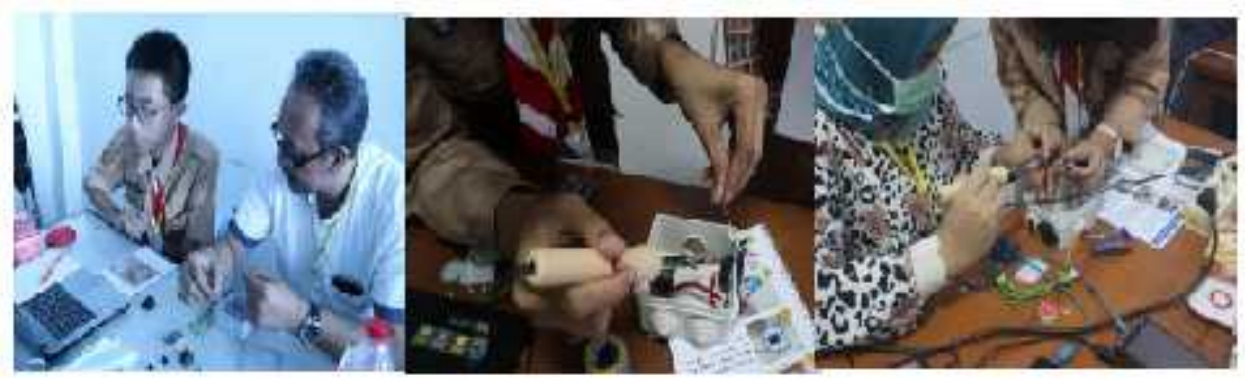

Gambar 6 Dokumentasi acara perakitan komponen

Kegiatan ditutup oleh Kaprodi Sistel yakni Ahmad Fauzi, S.Si., M.T. (Gambar 8) sekaligus pemberian alat hasil Workshop secara simbolis kepada salah satu peserta. Penyerahan ini dilakukan oleh Ketua Pelaksana didampingi oleh Kaprodi Sistel. Diharapkan, sekolah yang telah diundang dapat segera menerapkan mesin kehadiran yang telah diberikan tersebut. Gambar 9 merupakan dokumentasi foto bersama diujung kegiatan workshop (Pukul 17.00 WIB), yaitu peserta siswa \& guru, panitia pelaksana termasuk asisten instruktur, dan para Dosen Sistem Telekomunikasi UPI Purwakarta.

Peserta diberikan SPPD yang telah ditandatangani oleh pejabat kampus. Sertifikat sebenarnya dapat dibagikan tepat saat peserta meninggalkan gedung, adapun desain sertifikat ada 3 buah: panitia, pelaksana, dan peserta seperti yang ditunjukkan pada Gambar 10.

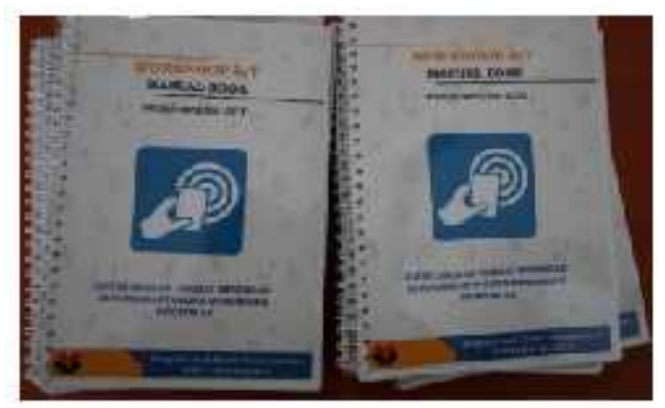

Gambar 7 Tampilan Manual Book 

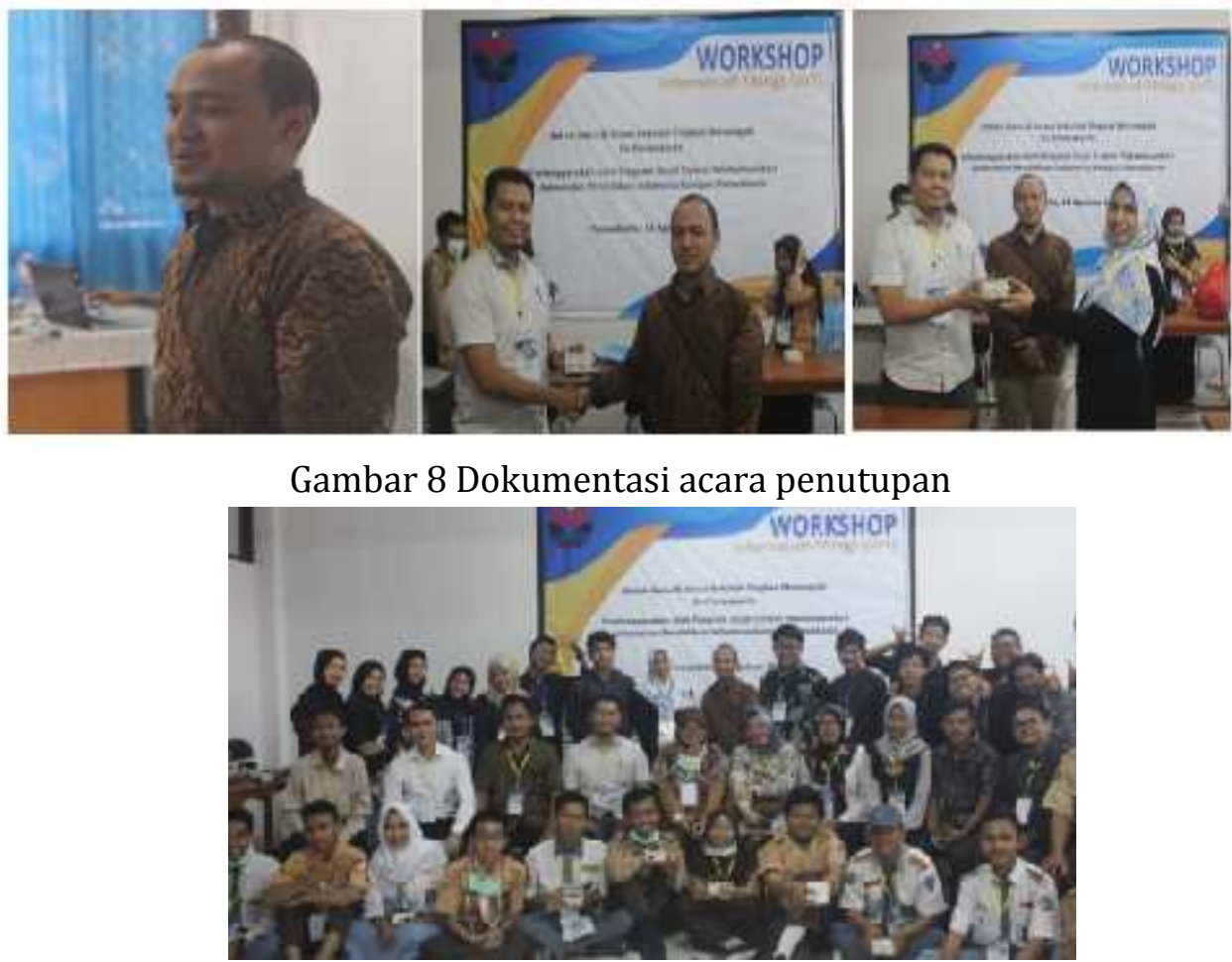

Gambar 9 Foto bersaman usai kegiatan workshop

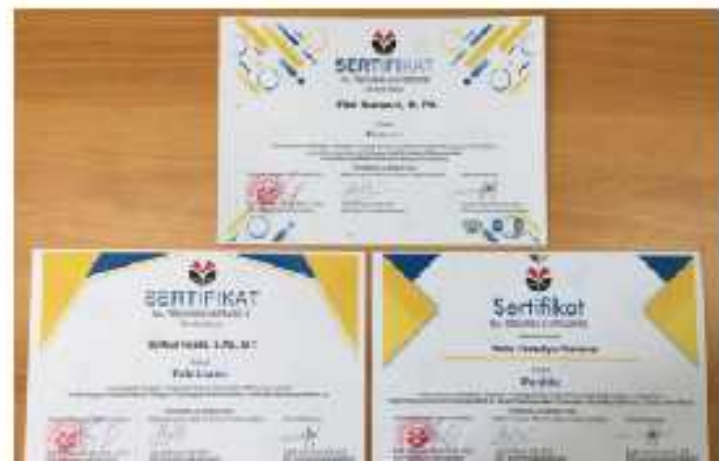

Gambar 10 Sertifikat kegiatan untuk peserta workshop (Guru \& Siswa undangan), panitia (Mahasiswa), dan pelaksana (Dosen)

\section{Evaluasi}

Untuk mengetahui respon peserta baik guru ataupun siswa pada kegiatan Workshop IoT, tahap selanjutnya adalah memberikan angket sebelum sesi terakhir (sesi dokumentasi foto). Dengan adanya form evaluasi ini, pelaksana PkM mendapati dua jenis data yakni kuantitatif dan kualitatif. Terdapat 12 (dua belas) butir pertanyaan dalam kuisioner dimana jawaban hanya berisi angka yakni skala 1 (satu) sampai skala 4 (empat) dengan keterangan sebagai berikut: skala 1 = sangat tidak setuju, skala $2=$ tidak setuju, skala $3=$ setuju, skala $4=$ sangat setuju. Kuisioner tertutup mencakup 3 (tiga) aspek utama, yakni isi materi, penyampaian materi, dan kegiatan praktik. Untuk data kuantitatif, perhitungan persentase mengacu pada (Fuada, 2015) ditunjukkan pada persamaan (1). Jumlah peserta adalah 24 orang, sehingga nilai maksimum apabila keseluruhan peserta menjawab skor 4 adalah 96 atau persentase maksimum $100 \%$. Sedangkan total nilai yang didapat, bergantung dari isian peserta. Apabila semua peserta memberikan nilai 1, jumlah terendahnya adalah 24 atau persentase minimum $25 \%$. Selisih antara persentase maksimum terhadap persentase minimum adalah $75 \%$. 


$\begin{array}{cccc}t \iota & n & y & d\end{array}-x 100 \%$

Tim PkM menggunakan empat tingkatan skala likert (1 s.d. 4) seperti yang telah dijelaskan sebelumnya, dengan demikian kelas interval juga dibagi menjadi empat tingkatan. Nilai interval didapatkan $18,75 \%$, yang didapat dari perhitungan sebagai berikut: $(75 \%) /(4$ interval). Hasil konversi sekaligus tingkat kepuasan ditunjukkan pada Tabel 3.

Tabel 3 Tingkat kepuasan peserta terhadap pelaksanaan Workshop IoT

\begin{tabular}{|c|c|c|}
\hline No. & Persentase & Keterangan \\
\hline 1. & $81,26 \%-100,00 \%$ & Sangat puas \\
\hline 2. & $62,51 \%-81,25 \%$ & Puas \\
\hline 3. & $43,76-62,50 \%$ & Tidak puas \\
\hline 4. & $25,00 \%-43,75 \%$ & Sangat tidak puas \\
\hline
\end{tabular}

Peserta dianggap puas apabila respon yang diberikan berada pada rentang $(62,51 \%$ $81,25 \%)$ dan $(81,26 \%$ - 100\%). Berdasarkan kriteria tersebut, maka didapatkan hasil sebagai berikut: 1) peserta puas terhadap isi (substansi) materi, dalam hal ini adalah IoT dengan persentase $81 \%$; 2) cara penyampaian materi/teori oleh instruktur dianggap sangat memuaskan dengan persentase $82 \%$; dan 3) menurut peserta, kegiatan praktik sudah sangat memuaskan karena persentase diatas 81,26\%. Secara lengkap dipresentasikan pada Tabel 4 .

Tabel 4 Respon para peserta Workshop terhadap kegiatan

No

Pernyataan

\section{Percentage}

Isi Materi:

1 Tema Workshop (Internet-of-things) menarik bagi saya $\quad 86 \%$

2 Meteri Workshop sesuai dengan yang saya butuhkan 76\%

3 Materi Workshop terorganisasi dengan baik 82\%

$81 \%$

4 Materi padat dan jelas sehingga cukup memberikan pemahaman saya $\quad 80 \%$

\section{Penyampaian Materi}

5 Instruktur sangat memahami materi yang disampaikan

$82 \%$

6 Alokasi waktu instruktur untuk menyampaikan materi menurut saya sudah cukup

$82 \%$

Instruktur menyampaikan isi materi dengan baik, mudah dimengerti,

$78 \%$

$82 \%$ dan diikuti

8 Instruktur melayani diskusi dan memberikan feedback

$86 \%$

\section{Kegiatan Praktik}

9 Manual book telah disediakan dengan kualitas yang baik

10 Manual book mudah dimengerti

$88 \%$

11 Asisten instruktur telah memfasilitasi kegiatan praktik dengan baik

$81 \%$

$86 \%$

$85 \%$

12 Alokasi waktu untuk pelaksanaan praktik sudah mencukupi

$84 \%$

Sementara data kualitatif didapatkan dari jawaban peserta dalam bentuk esai. Peserta menuliskan hal-hal yang menurut mereka penting namun tidak tercantum dalam keduabelas item yang tersedia dalam angket, seperti konsumsi, keramahan instruktur/panitia, keterjangkauan tempat pelaksanaan Workshop, fasilitas, dsb. Kemudian peserta juga mengisi 
saran-saran dalam rangka perbaikan pelaksanaan Workshop serupa dimasa yang akan datang. Berikut ini merupakan cuplikan dari tanggapan-tanggapan para peserta:

- Semua fasilitas udah OK dan konsumsi lumayan OK tapi nasi nya lebih banyak ya

- Lebih di lengkapi lagi alat-alat prakteknya tiap meja peserta tetapi meskipun kekurangan salah satu alat, panitia responnya cepat. Dengan adanya Workshop ini bukan hanya SMK saja tetapi SMA pun bisa belajar tentang perakitan modul yang sebelumnya tidak pernah diajarkan di sekolah dan bisa merasakan betapa menariknya Workshop ini.

- Dalam konsumsi, sudah sangat baik, peserta sudah diberi konsumsi dengan sebaik mungkin. Untuk keramahan panitia bagi saya sudah cukup, akang tetehnya baik-baik dan ramahramah tidak ada yang menurut saya jutek ataupun judes, semuanya baik-baik. Untuk fasilitas panitia sudah mempersiapkannya dengan sebaik mungkin, jadi peserta Workshop tidak kekurangan bahan saat praktik.

- Instruktur/panitia bekerja sama dengan baik, tempat Workshop nyaman dan tidak terlalu banyak yang diundang jadi bisa kepantau sama panitia.

- Semuanya baik.

- Panitia IoT ini sangat fast respond dan friendly jika peserta ada masalah dalam pembuatan mesin panitia IoT selalu melayani.

- Konsumsi sangat baik. Keramahan sangat baik. Fasilitas baik. Keterjangkauan baik.

- Supaya lebih sering lagi dilaksanakan kegiatan semacam ini.

- Workshop ini sangat penting karena Workshop ini sangat bermanfaat dan dapat menambah wawasan terutama di zaman yang serba modern ini. Akan tetapi di dalam modulnya kurang ada rangkaian atau diagram rangkaiannya kurang jelas. Fungsi-fungsi dari komponen itu tersebut tidak dijelaskan dan langkah-langkah pemasangannya juga kurang jelas karena yang mengikuti Workshop ini tidak semuanya dari SMK tetapi ada juga dari SMA dan MA yang mungkin dalam sesi pemahamannya kurang.

- Semoga kedepannya pelaksanaan Workshop berupa software (perangkat lunak).

- Tambah peserta. MC lebih siap lagi. Sediakan kuis dan doorprize. Tim Panitia lebih ramah lagi terhadap peserta (sudah bagus sih sebenarnya). Keep up the Great Work!

- Semuanya sudah sangat baik, hanya manajemen waktunya saja. Di surat undangan tertulis jam 07.00, namun baru dibuka satu jam lebih dari waktu yang ditentukan.

Berdasarkan tinjauan tim PkM dari isian para peserta tersebut, kegiatan Workshop ini sudah sangat baik, dari sisi konsumsi (meskipun ada salah satu yang menyarankan ditambah volume konsumsinya), keramahan dan fast response dari instruktur. Namun, yang menjadi evaluasi adalah manajemen waktu. Tim PkM sebelumnya sudah memberikan informasi bahwa pelaksanaan Workshop adalah Pukul 07.00 WIB dan panitia sudah ready pada jam 05.30 WIB, yang sebenarnya 07.00 WIB adalah waktu registrasi (alokasi 1 jam), bukan merupakan acara inti (mulai pembukaan, sambutan, sampai photo session). Sehingga kegiatan dimulai pada pukul 08.10 WIB sudah tepat, dalam hal ini terjadi misscommunication antara mahasiswa yang memberikan surat undangan ke pihak sekolah yang menerima surat undangan tersebut. Kemudian, supaya lebih interaktif perlu disediakan doorprize kepada para peserta yang sangat aktif dan antusias. Sedangkan kritik dan saran dari peserta (dengan tanpa menambah dan mengurangi apa yang telah mereka tulis), adalah sebagai berikut:

- Nasi nya di perbanyak dan perbanyak materinya.

- Untuk pemateri menggunakan mic agar lebih jelas lagi.

- Dalam sebuah penataran tentang suatu aplikasi misalnya jarang sekali ada tindak lanjut pengembangan program yang dilaksanakan secara continue, harap diperhatikan. 
- Untuk sarannya mungkin untuk penerangan materi bisa diperjelas kembali agar materi, yang disampaikan bisa lebih dipahami kembali oleh peserta Workshop.

- Untuk manual book nya saya saran kan dibuat supaya para peserta menjadi mengerti.

- Workshop ini sudah berjalan dengan baik, panitia bisa mendampingi peserta dan membimbing peserta. Semoga ke depan bisa mengadakan Workshop untuk kemajuan AI di sekolah.

- Semoga kedepannya lebih baik lagi.

- Setelah IoT ini diharapkan dapat memberikan/menambah materi lainnya yang berhubungan dengan smar city guna mendukung industry 4.0. Mohon untuk akses internet agar diperbarui, karena IoT membutuhkan akses internet.

- Ketika peserta merakit komponen alat hendaknya dibantu dengan tampilan video/gambar melalui projector. Gambar pada manual book terlalu kecil.

- Kesalahan yang kurang saya pahami adalah pada symbol yang terdapat pada papan PCB seperti symbol kapasitor non polar, sedangkan disini kita menggunakan kapasitor yang memiliki polar/kutub. Sehingga susah ketika akan menggunakan kapasitor dan membedakan penempatan kutub-kutub kapasitor pada kaki-kaki nya. Terimakasih

- Kegiatan/acara Workshop IoT ini sudah sangat baik dan saat pemberian praktik langsung sangat cepat tanggap untuk memberikan masalah/kendala yang dialami oleh peserta. Saran saya semoga acara seperti ini bisa diadakan kembali tahun-tahun berikutnya.

- Tambah peserta agar tambah besar manfaat yang diberikan/didapat.

Secara keseluruhan, saran-saran para peserta adalah memberikan hal-hal yang positif kepada pelaksana PkM, misalnya adalah perlunya ditambah peserta, harapan agar kegiatan seperti ini lebih banyak dilaksanakan oleh Prodi Sistel, tambahan waktu karena satu hari sebenarnya cukup singkat untuk memberikan materi teori sekaligus praktik terutama bagi para guru dan siswa yang bukan dari background elektronika/fisika. Kemudian, perlunya ditambah konsumsi. Hal ini wajar, karena faktor budget sehingga konsumsi hanya diberikan dua kali yakni snack pada pagi hari dan makanan berat pada siang hari. Namun, memang sudah selaiknya sore hari juga disediakan oleh pelaksana PkM karena kegiatan ini cukup mengkonsumsi energi. Beberapa poin yang menjadi perbaikan adalah manual book menurut para peserta masih kurang jelas (komunikatif). Idealnya sebelum dipakai oleh peserta, manual book harus melalui proses validasi terlebih dahulu sehingga tidak ada misscommunication pada instruksi-instruksi yang ada di manual book (Hasanah et al., 2018). Saran lainnya adalah materi harus lebih banyak (komperhensif), dan penggunakan pengeras suara. Meskipun ruangan tertutup dan peserta sedikit, ternyata fungsi mic sangat diperlukan dalam kegiatan semacam ini (Novianto, 2016). Penggunaan Mic dengan pengaturan yang tepat agar tidak menimbulkan noise atau derau sehingga peserta workshop nyaman mengikuti kegiatan.

\section{Analisis Faktor Pendukung Dan Penghambat Kegiatan Workshop}

Kegiatan pelatihan ini dapat berjalan dengan lancar disebabkan adanya dukungan dari pihak kampus, yakni Direktur kampus UPI Purwakarta, Wakil Direktur kampus UPI Purwakarta, serta Kaprodi Sistem Telekomunikasi. Para peserta cukup antusias dengan memberikan pendapat saat sesi diskusi dan tanya jawab. Kegiatan Workshop ini juga didukung oleh jaringan internet yang memadahi yang memang secara khusus disiapkan oleh bagian TIK. Kemudian, dukungan sarana dan prasana dari Departemen UMPER UPI Purwakarta serta ke-15 mahasiswa yang membantu menyiapkan alat \& bahan, setting 
ruangan, sumber listrik. Juga bantuan dari bagian kebersihan \& keamanan, serta media yang meliput kegiatan Workshop ini. Adapun hasil liputan disurat kabar tercetak maupun online pada link https://www.pasundanekspres.co/headline/upi-purwakarta-miliki-prodi-sistel/ dan http://poskotanews.com/2019/08/15/guna-menjawab-era-revolusi-industri-4-0-prodisistel-upi-gelar-workshop/

Namun, beberapa hal diidentifikasi sebagai faktor penghambat yakni beberapa tim tidak tuntas dalam menyelesaikan praktikum, karena salah penyambungan dan gagal tersambung kejaringan. Troubleshooting sebenarnya dapat dilakukan apabila waktu tersedia, sementara permasalahan muncul saat hari sudah sore. Panitia telah memberikan alokasi waktu sekitar 1 jam dan beberapa yang gagal tersebut dapat diperbaiki, sisanya masih belum berhasil. Selanjutnya, beberapa peserta guru yang hadir adalah dari BK, sehingga teori-teori terkait dengan materi praktikum tidak sepenuhnya dapat diterima dengan baik. Untuk meminimalisir hambatan ini, seyogyanya memang Workshop diselenggarakan lebih dari satu hari. Pemerataan peserta sesuai dengan bidang keilmuan/kepakarannya (fax) sehingga mereka dapat menyerap pengetahuan secara maksimal. Hambatan lain adalah terkait dengan pembagian sertifikat, terjadi kesalahan teknis sehingga sertifikat diberikan keesokan harinya. Beberapa sertifikat tertukar antar sekolah lainnya karena yang menerima bukan merupakan peserta yang bersangkutan. Hal ini dapat menjadi evaluasi dari panitia yang datang ke sekolah tersebut.

\section{SIMPULAN}

Dari hasil pelaksanaan kegiatan PkM ini, dapat disimpulkan bahwa antusiasme sekolah tingkat menengah di Kabupaten Purwakarta terhadap kegiatan Workshop IoT relatif tinggi. Hal ini dibuktikan melalui partisipasi aktif para peserta terhadap kegiatan Workshop IoT. Sedangkan dari hasil analisa angket, dapat disimpulkan bahwa penyelenggaraan Workshop IoT secara keseluruhan dinilai telah terselenggara dengan baik jika ditinjau dari fasilitas (sarana dan prasarana), konsumsi, respon pelayanan panitia dan dari materi yang disampaikan. Adapun beberapa hal yang menjadi catatan kami untuk diperbaiki sekaligus menjadi saran untuk kegiatan serupa kedepannya adalah durasi penyelenggaraan Workshop agar dipertimbangkan menjadi lebih dari satu hari, penambahan media penyampaian materi seperti video dan penggunaan microphone serta pengeras suara untuk menunjang keseluruhan kegiatan Workshop walaupun diselenggarakan di ruangan tertutup yang relatif kecil dengan peserta yang tidak terlalu banyak. Selanjutnya, diperlukan tindak lanjut dari seusainya kegiatan Workshop. Diperlukan survei awal kepada para peserta terkait Workshop apa yang dibutuhkan (seperti permintaan pelatihan), sehingga peserta sasarannya lebih jitu karena sesuai dengan yang mereka perlukan, tentu saja dalam kaitannya dengan IoT atau penunjang kompetensi pada era industry 4.0 .

\section{DAFTAR RUJUKAN}

Afriliana, I., Budihartono, E., \& Sabanise, Y. (2018). Pengenalan Internet Of Things (Iot) untuk Peningkatan Softskill pada Siswa SMA N 5 Tegal. Jurnal Pengabdian Masyarakat Progresif Humanis Brainstorming, 1(2), 92-97.

Aji, K. P., Darusalam, U., \& Nathasia, N. D. (2020). Perancangan Sistem Presensi Untuk Pegawai Dengan RFID Berbasis IoT Menggunakan NodeMCU ESP8266. JOINTECS (Journal of Information Technology and Computer Science), 5(1), 25. 
Ananda, R., \& Amin, M. (2019). Workshop Pelatihan Perancangan Internet of Things Berbasis Arduino UNO Jenis r3/r3 SMD di SMK swasta Karya Utama Kota Tanjungbalai. Jurnal Pengabdian Kepada Masyarakat, 2(2), 6.

Fauziah, H. Y., Sukowati, A. I., \& Purwanto, I. (n.d.). Rancang Bangun Sistem Absensi Mahasiswa Sekolah Tinggi Teknik Cendekia (Sttc) Berbasis Radio Frequency Identification (Rfid). 8.

Fuada, S. (2015). Pengujian Validitas Alat Peraga Pembangkit Sinyal (Oscillator) untuk Pembelajaran Workshop Instrumentasi Industri. 8.

Hasanah, N., Mahali, M. I., \& Wulandari, B. (2018). Pengembangan Trainer Internet Of Things Sebagai Media Pembelajaran Pada Mata Kuliah Internet Of Things. Elinvo (Electronics, Informatics, and Vocational Education), 3(2), 19-29.

Irmansyah, M., \& Madona, E. (2019). Penerapan IoT Menggunakan Mikrokontroler NodeMCU ESP8266 untuk Meningkatkan Kompetensi Siswa SMK. 1(1), 5.

Manfaluthy, M., \& Ekawati, R. (2019). Pelatihan Internet Of Things (Iot Trainer) Berbasis Esp8266 pada SMK Al-Muhadjirin Bekasi. Prosiding Seminar Nasional Pengabdian Masyarakat LPPM UMJ, 0(0), Article 0.

Novianto, I. (2016). Implementasi Eliminasi Derau Dengan Metode Tapis FIR Pada Feedback Pengeras Amplifier dan Microphone Berbasis SAM3X8E. 6.

Purwiantono, F. E., Romli, M. S., \& Aditya, A. (2019). Pemanfaatan RFID (Radio Frequency Identification) sebagai Alternatif Absensi Siswa (Studi Kasus: SMK Ar-Rahmah Sukabumi, Jawa Barat). Jurnal Teknoinfo, 13(2), 118.

Setiawan, E. B., \& Kurniawan, B. (2015). Perancangan Sistem Absensi Kehadiran Perkuliahan dengan Menggunakan Radio Frequency Identification (RFId). 6.

Setiawan, H. S. (2018). Pelatihan Guru dalam Penggunaan Internet of Things pada Madrasah Darussa'adah. E-Dimas: Jurnal Pengabdian kepada Masyarakat, 9(2), 167.

Setyowati, E., Fuada, S., Suranegara, G. M., Pratama, H. P., Hadi Putri, D. I., \& Ichsan, I. N. (2019). Mesin Absensi RFID berbasis Internet-of-Things (IoT) untuk Meningkatkan Pengetahuan Siswa di Purwakarta terhadap Teknologi. DIKEMAS (Jurnal Pengabdian Kepada Masyarakat), 3(2).

Wagyana, A. (2019). Jurnal Ilmiah Setrum Article In Press. 10.

Widayanti, A. T. E. (2019). Penerapan Absensi Berbasis Sistem Barcode dalam meningkatkan kedisiplinan siswa di Madrasah Aliyah Nurul Huda Sedati Sidoarjo [Undergraduate, UIN Sunan Ampel Surabaya]. http://digilib.uinsby.ac.id/38923/ 